\title{
Object permanence in four species of psittacine birds: An African Grey parrot (Psittacus erithacus), an Illiger mini macaw (Ara maracana), a parakeet (Melopsittacus undulatus), and a cockatiel (Nymphicus hollandicus)
}

\author{
IRENE M. PEPPERBERG and MILDRED S. FUNK \\ Northwestern University, Evanston, Illinois
}

\begin{abstract}
Four psittacids-an African Grey parrot, an Illiger macaw, a cockatiel, and a parakeet-were tested on object-permanence tasks that are commonly used to assess levels of understanding in human infants during their first 2 years. These birds showed Stage 6 competence, demonstrating that object permanence is not limited to mammals. The results for these birds were comparable to those of an African Grey parrot that had been trained in interspecies communication prior to object-permanence testing. Our findings thus suggest that although language-like behavior provides a communication channel that facilitates testing, such language training is unlikely to affect the outcome of the tests.
\end{abstract}

Object permanence-the notion that objects are separate entities that continue to exist when out of sight of the observer-would seem to be one of the more important cognitive concepts, and thus an appropriate topic for comparative study. Object permanence was nevertheless largely ignored during almost a century of comparative research (note Burghardt, 1984; Macphail, 1987), possibly because it was considered both innate and unitary-a concept so basic that researchers could not imagine how any organism could exist without it (see Flavell, 1985). Piaget was the first to suggest that this concept was not inborn, but was acquired and could be acquired to varying degrees. Only after Piaget's writings became widely available (Piaget, 1971, 1978, 1980) did researchers routinely test animals on the concept of object permanence (e.g., Chevalier-Skolnikoff, 1976, 1981, 1989). These studies, which involved nonhuman primates and a few nonprimate mammals, have demonstrated that the capacity of nonhuman mammals for solving some objectpermanence problems is comparable to that of humans.

Additional data suggest that nonmammals may also comprehend object permanence. Observation of the behaviors of several avian species in seminatural surroundings and in the wild (e.g., nutcrackers, Nucifraga colum-

We thank the Ravid family, Jean Benzies, Linda Rusin, and Ann Shanks for their patience and for allowing their birds to be used in our study, Lois Sears for assisting with the testing, and Vincent $M$. LoLordo and two reviewers for their comments on an earlier version of the manuscript. I.M.P. thanks the National Science Foundation for support (BNS 84-14483). The authors' address is Department of Anthropology, Northwestern University, 1810 Hinman Avenue, Evanston, IL 60208-1310. biana, Kamil \& Balda, 1985; Vander Wall, 1982; European jays, Garrulus glandarius, Bossema, 1979; jackdaws, Corvus monedula, Etienne, 1976-1977; Lorenz, 1970; marsh tits, Parus palustris, Sherry, 1982; Shettleworth \& Krebs, 1982; chickadees, Parus atricapillus, Sherry, 1984; Shettleworth \& Krebs, 1986) provide evidence for behaviors such as recovery of cached food or cavity nesting that would appear to require a concept of object permanence. ${ }^{1}$ And although laboratory studies initially provided evidence for only a limited concept of object permanence in birds such as domestic chickens (Etienne, 1973a, 1973b), a recent study (Pepperberg \& Kozak, 1986) has demonstrated the full capacity in an African Grey parrot (Psittacus erithacus).

The results of the Pepperberg and Kozak (1986) study, however, might not be representative of psittacine abilities. African Greys, for example, have scored better than other psittacids on tests of certain cognitive capacities (Kolar, 1972; Rensch, 1956). Moreover, the subject of the Pepperberg and Kozak study, Alex, had received considerable prior training on tasks involving animal-human communication (Pepperberg, 1979, 1981, 1983, 1987a, 1987b), and some investigators (Hall, Braggio, Buchanan, \& Nadler, 1982; Hall et al., 1980; Premack, 1983, 1984) have suggested that "language-trained" subjects have special skills and abilities that enhance their capacities for problem-solving.

The present study, therefore, had two objectives: (1) to assess the ability of a variety of nonlanguage-trained psittacids to solve standard object-permanence tasks, and (2) to compare the performance of these nonlanguagetrained psittacids with that of Alex. Comparisons among the nonlanguage-trained psittacids would enable us to learn 
whether object permanence, like certain more advanced cognitive capacities (e.g., numerical competency; Koehler, 1943, 1950), might vary across species. Comparisons between Alex and the nonlanguage-trained birds, particularly an untrained African Grey, would provide information on how such training might influence a study of object permanence.

\section{Background}

According to Piaget $(1953,1954)$, development of the object concept is the earliest step in intellectual development and is a prerequisite for successful interaction with the external world. A subject that comprehends the permanence, separateness, and continuity of external objects can also comprehend its own identity as a separate entity among all others in its environment, and can thus situate itself in time and space. Piaget described the development of this concept in terms of a sensorimotor period of six stages, each stage showing progressive manipulatory skills and increasing awareness of self and surroundings.

Although the Piagetian framework was designed for use with humans, its methodology is consistent with that of animal studies and thus facilitates cross-species comparisons of observational and experimental data. The specific behavioral features that the Piagetian framework uses to categorize narrative data (observations and note-taking about the subject's activity in its natural habitat or in the laboratory; see Chevalier-Skolnikoff \& Poirier, 1977) are similar to those of the early ethologists (e.g., Lorenz, 1970). Moreover, experiments based on the Piagetian framework directly measure levels of performance on specific tasks that are often easily adaptable for use with many species (Chevalier-Skolnikoff, 1989). A series of tasks designed by Uzgiris and Hunt (1975; see Appendix) to compare capacities for object permanence in developing human infants has, for example, also been used in animal studies (e.g., chimpanzees, Pan troglodytes: Hallock \& Worobey, 1984; Wood, Moriarty, Gardner, \& Gardner, 1980; lowland gorillas, Gorilla gorilla: Redshaw, 1978; for a review of other animal studies, see Doré \& Dumas, 1987).

The Uzgiris and Hunt (1975) scale not only can be used to measure relative rates of development across subjects, but can also be administered in adulthood to assess an ultimate level of acquired competence (Triana \& Pasnak, 1981). The scale thus enabled us to compare adult subjects of varying ages. The level of competence is determined by performance on an increasingly difficult series of 15 tasks. Success on a later task presupposes ability on earlier ones. Successful completion of specific sets of tasks can be correlated with Piaget's six stages of understanding of object permanence (e.g., Wadsworth, 1984; see below). The Uzgiris and Hunt scale of tasks thus not only facilitates cross-species comparisons of the concept of object permanence, but, by dividing the Piagetian stages more finely, also provides additional within-stage data on behavioral similarities and differences across species.
Recently, however, researchers have argued whether the Uzgiris and Hunt (1975) scale provides the best basis for comparison. The arguments center on two issues: (1) whether such standardized tests are sensitive enough to pinpoint the age at which many of these abilities emerge (e.g., Bower, 1982; Flavell, 1985; Harris, 1983), and (2) whether the tasks actually quantify the existent cognitive level of the subject or, instead, measure the level of proficiency reached with respect to training, learning, and memory (Bjork \& Cummings, 1984; Doré \& Dumas, 1987). The first issue is not relevant if, as in our study, the scale is used to determine the relative ultimate level of achievement rather than relative rates of development. The criticism contained in the second issue is more difficult to counter (see General Discussion); however, the invariance of the procedures ensures that the effects of learning, training, and memory would influence the results for all subject species equally. Furthermore, standardized tasks such as those of Uzgiris and Hunt prevent the variations in experimental design between laboratories that often render ambiguous the results of other comparative studies (see Wood et al., 1980; note also Bateson, 1979; Kroodsma, 1982; Kroodsma, Baker, Baptista, \& Petrinovich, 1984).

\section{METHOD}

\section{Subjects}

We tested 1 individual from each of the four subject species. In object-permanence studies, single-subject designs are known as "power studies" (Triana \& Pasnak, 1981). If the subject of a power study reliably demonstrates object permanence, the implication is that this aptitude is within the capacity of that species. Negative results from one subject in such a study, however, do not necessarily imply the lack of such an aptitude for the species as a whole (see discussion in Triana \& Pasnak, 1981).

The 4 subjects were all pets. They were: Wok, a 13-year-old African Grey parrot (Psittacus erithacus); Fred, an adult Iliger mini macaw (Ara maracana); Bruce, an 18-month-old parakeet (Melopsittacus undulatus); and Yellow Bird, an 8-month-old cockatiel (Nymphicus hollandicus).

\section{Apparatus: Search Objects and Covers}

Objects for which the birds searched included food and nonfood items. Food items included seeds, grapes, crackers, peanuts, and ice cream or water in a small cup for Fred; rolled oats, cream cheese, banana, and egg yolk for Bruce; jelly beans, cookie pieces, chocolate matzoh, and cherries for Wok. Fred and Bruce were also tested with mirrors, yarn, and a hair clip. Wok was tested only with food because scheduling difficulties prevented replication with nonfood items. Yellow Bird was tested only with nonfood items-rings, clips, and a key chain. We chose these classes of objects on the basis of the extent to which they would motivate the subjects (see Discussion). For all subjects, these items were hidden under crumpled paper toweling or newspaper, paper plates, bags, or measuring cups.

\section{Tasks}

The Uzgiris and Hunt (1975) Scale 1 tasks used in this experiment are given in the Appendix. Tasks 1 and 2 test if a subject can visually follow a slowly moving and then disappearing object, and correspond, respectively, to Piaget's Stages 2 and 3. Tasks 3 and 4 test Stage 4 , the ability to retrieve an object that is, respectively, 
partly hidden and then completely hidden under a single cover. Task 5 is the first to test a subject's response when there are two possible hiding places. In Tasks 6 and 7, the hiding place alternates between two and then three covers, respectively. Task 8 involves successive visible displacements: an object, in full view in the investigator's hand, is passed under successive covers until it is hidden under the designated cover. This task tests the ability to follow an object's movement in order to search the location where it has most recently been seen. In Task 9, the experimenter places an object under three superimposed covers to gauge the subject's persistence in removing covers to obtain the object. A subject that succeeds on Tasks 5-9 is considered to have reached Stage 5. Tasks 10-13 are similar to Tasks 4-7, except that the object is not in full view during a transfer. The object is, instead, hidden in a small container (the implementing cover) and then placed, respectively, under one or a choice of two or three covers. Only then is the subject shown that the implementing cover is empty. Task 14 repeats Task 8 , but the object is not seen after it is initially placed in the hand or cup as the investigator moves it among the covers. Task 15 is a "trick": the object is hidden under the first cover but the investigator's hand continues to move under the other covers so that the animal is led to believe that the object is under the last cover, as in the previous task. In Tasks 10-15, the subject cannot view the transfer but can only infer that it has occurred. Tasks 10-15 thus presumably require inferential, rather than perceptual, abilities, and successful completion of these tasks indicate that the subject has achieved full Stage 6 understanding of object permanence.

We sometimes presented more complex tasks before simpler ones had been completed (note Pepperberg \& Kozak, 1986). The order in which the tasks are given is important only for developmental studies, and the shift to a task that was different and more challenging helped to focus the attention of the subject. This shift also showed that the subject was not being trained to do the tasks in a step-bystep manner, because success at these more complex tasks was then independent of the bird's experience with the simpler tasks (see General Discussion).

\section{Procedure}

At least 2 persons administered the trials. One was often the bird's owner and the other 1 or 2 were the experimenters. Because the birds were pets and not always at ease with strangers, the owner's presence could be required to reassure the animal that the experimenter was nonthreatening. All humans present at the experiment took all the roles (i.e., hiding the objects, observing the action, and scoring the results).

The subjects would usually work only for sessions of short duration. A session normally lasted $1 \mathrm{~h}$ and consisted of only three or four tasks, beginning with a repetition of the last task done in the previous session. The repetition tested a subject's willingness to work on a given day: failure to repeat a task that had previously been performed usually indicated motivational problems and separated such problems from the inability of the subject to perform the task. To maintain the subject's motivation, the experimenters varied objects or foods between trials and allowed the birds to eat the food or play with the toy they had found (see Dore \& Dumas, 1987). Even with this protocol, the birds generally became uncooperative after three or four tasks.

Intervals between sessions and the number of sessions needed to complete the 15 tasks varied among subjects. Sessions occurred at the owners' convenience, and thus not necessarily at regular intervals. Bruce was seen seven times in 6 weeks. Seven visits to Fred were spread over 7 months. Ten sessions with Wok took place over 5 months. Yellow Bird was tested during a 10-day period, with a brief visit 3 months later to retest one task. We could not impose upon all the owners to do three complete series of 15 tasks, as suggested by Uzgiris and Hunt (1975); only with Yellow Bird were we able to complete three series. Many of the tasks for most of the subjects were, however, repeated at least once because of the one-task review at the outset of sessions and the retesting on food or nonfood items.

\section{Procedural Difficulties}

The protocol as an aversive situation. Most of the birds found testing somewhat aversive. They had never before had an object placed within their reach that was then hidden before it could be obtained. Thus, the first time an object was completely hidden (Task 4), 2 birds (Wok and Yellow Bird) initially engaged in displacement behaviors: they would head-bob, pluck at their feathers, or emit distress calls similar to those used in other unfamiliar situations. One subject, Wok, also reacted fearfully when novel objects were used as covers (note Zentall, Edwards, Moore, \& Hogan, 1981; Zentall \& Hogan, 1974). Wok's reaction was specific to novelty, because objects of familiar weight and material presented no problem.

Cuing. Experimenters who use household pets as subjects must be especially careful to avoid cuing. A pet may be particularly responsive to nonverbal cues because of its close relationship with its owner. An owner or the investigator may stare at the correct cover, for instance, or may unknowingly make a slight movement when the subject approaches the correct cover. None of the birds in the present study, however, appeared to wait for reactions of either the experimenters or their owners before or during their actions. The subjects would sometimes respond to verbal requests to approach the covers ("Go find the mirror"), but from that point on did not pause or look to the people for directions.

Physical nonverbal movements may not be the only sources of extraneous cues; for example, there may be odor cues if the object to be located is food. Although the degree of olfactory sensitivity in birds is not well documented (Stettner \& Matyniak, 1968), the relative importance of cuing by this sense appears to vary across species (Harriman \& Berger, 1986). Avian olfactory bulbs are, however, generally small compared to those of mammals (Macphail, 1982), and the behavioral data from our subjects suggest that odor was unlikely to be an important factor in the birds' searches. The birds made similar numbers of mistakes whether the hidden object was food or nonfood. Sometimes the birds would eat little of the food rewards. Although Wok was tested only with food items, these were covered by plastic cups that had all contained food, or by newspapers or paper bags that were also somewhat odorous. Also, for all the birds, crumbs from previous trials with different foods were not removed from the table surface, thus providing a distracting effect.

Triana and Pasnak (1981) have commented on the possibility of inadvertent cuing. They noted that some evident cues are actually built into the early tasks, and that such cues are therefore present for all species that have been tested, including humans. Later tasks, in contrast, are designed to expose responses to cuing. Task 15, for example, specifically tests for odor cues because the object may be left under the first screen, but the investigator gives the appearance of placing the object elsewhere. Our subjects were always "tricked" (see below). Moreover, even obvious pointing to the correct cover does not help animals that do not understand the task (or the indicative nature of pointing), or, alternatively, have no motivation to repeat an already correct performance (note Pepperberg \& Kozak, 1986).

Other practical considerations. Not all subjects of a given species can be tested. We rejected 2 parakeets as subjects because of specific behavioral idiosyncrasies. One parakeet would not leave her cage and therefore could not easily be tested. Another flew constantly and, although he did complete the first five tasks, would not alight frequently enough to attend to hidings on the subsequent tasks. These 2 birds may have understood object permanence, but their behavioral characteristics interfered with the possible demonstration of this ability 


\section{Scoring Criterion}

The performance criterion was similar to that used in previous studies: no more than one incorrect trial in two of three tests of the Uzgiris and Hunt (1975) tasks (see Pepperberg \& Kozak, 1986; Wood et al., 1980). A trial was done correctly if the subject uncovered the hidden item or performed one of the other acceptable actions within $30 \mathrm{sec}$ of the hiding of the item. For each of the tasks, Uzgiris and Hunt list three to five alternative erroneous actions that subjects could perform, from pulling off the wrong cover to losing interest in the object or doing a haphazard search. Correct searches must be done consecutively three, four, or five times as noted for each task. Mistrials were recorded when our subjects (1) failed to go to any of the sites within $30 \mathrm{sec}$, (2) removed and immediately manipulated the covers without searching for the hidden object, or (3) went so fast that they interfered with the placement of the object. Errors were recorded when the subjects lifted and searched under the wrong cover.

\section{RESULTS AND DISCUSSION}

Except for the parakeet, Bruce, who died before testing could be completed, all subjects met the criteria for full Stage 6 object permanence according to the Uzgiris and Hunt (1975) scale. The results are summarized in Tables 1 and 2 . Because there were often individual differences in how the subjects solved the tasks (note Fletcher, 1965), detailed descriptions of such behaviors are given below.

\section{Table 1}

Results of Single-Trial Sessions Per Task for Wok, Bruce, and Fred

\begin{tabular}{cccc}
\hline \multicolumn{3}{c}{ Bird } \\
\cline { 2 - 3 } Task & Wok & Bruce \\
\hline \multicolumn{4}{c}{ Visual Pursuit of Slowly Moving Objects } \\
1 & 3 & 3 & 3 \\
2 & 3 & 3 & 3 \\
\multicolumn{4}{c}{ Search for Simply Hidden Objects } \\
3 & 3 & $3 *$ & 3 \\
4 & 3 & 4 & 3 \\
5 & 3 & 2 & 2 \\
6 & 3 & $3(1)$ \\
7 & $5(1)^{*}$ & 5 & $5 *$ \\
& Search Following More Complex Findings & \\
8 & $3(1)^{*}$ & 3 & 3 \\
9 & 2 & 2 & 2 \\
& Search Following an Invisible Displacement & \\
10 & 3 & 3 & 3 \\
11 & 2 & $3(1)$ & $2 *$ \\
12 & $3(1)$ & 3 & 3 \\
13 & $6(1)^{*}$ & N/A & $5(1)$
\end{tabular}

Search Following Successive Invisible Displacements

\begin{tabular}{llll}
14 & $4^{*}$ & N/A & 4 \\
15 & $2 *$ & N/A & 2 \\
\hline
\end{tabular}

Note-Numbers represent the number of times the birds performed the action designated by Uzgiris and Hunt (1975) as critical for comprehension. The number of correct repetitions designated as necessary for comprehension is given in the Appendix. Numbers in parentheses represent the number of errors; see text for details. Asterisks represent mistrials. In most mistrials, the subjects manipulated the covers and ignored the hidden objects.
Table 2

Results of Multiple-Trial Sessions Per Task for Yellow Bird

\begin{tabular}{cccl}
\hline \multicolumn{4}{c}{ Number of Trials } \\
\cline { 2 - 4 } Task & Session 1 & Session 2 & Session 3 \\
\hline \multicolumn{4}{c}{ Visual Pursuit of Slowly Moving Objects } \\
1 & 3 & 3 & 3 \\
2 & 3 & 3 & 3 \\
\multicolumn{4}{c}{ Search for Simply Hidden Objects } \\
3 & 3 & 3 & 3 \\
4 & $3(2)$ & 3 & 3 \\
5 & 2 & 2 & 2 \\
6 & $3(1)$ & 3 & $3^{*}$ \\
7 & 5 & 5 & 5 \\
& Search Following More Complex Findings \\
8 & 3 & 3 & $3^{*}$ \\
9 & $2(1) *$ & 2 & 2
\end{tabular}

Search Following an Invisible Displacement

$\begin{array}{llll}10 & 3 & 3 & 3 \\ 11 & 2 & 3(1) & 2(1) \\ 12 & 3(3) & 3(2) & 3(5) \\ 13 & 5^{*} & 5(2) & 5\end{array}$

Search Following Successive Invisible Displacements

\begin{tabular}{llll}
14 & 4 & 4 & 4 \\
15 & 2 & 2 & 2 \\
\hline
\end{tabular}

Note-Numbers represent the number of times the bird performed the action designated by Uzgiris and Hunt (1975) as critical for comprehension. The number of correct repetitions designated as necessary for comprehension is given in the Appendix. Numbers in parentheses represent the number of errors; see text for details. Asterisks represent mistrials. In most mistrials, the subject manipulated the cover and ignored the hidden objects.

\section{Reaction to the Tasks and Apparatus}

Wok, the African Grey parrot. Wok initially tried to avoid the investigators and the search objects. He was particularly disturbed by novelty. When a novel cover (a paper towel) was introduced (Task 4), he did not remove it, but instead moved as far away as was possible, began to feather-pluck, and emitted distress calls. When we replaced the towel with a familiar cover (a paper bag), he responded appropriately. We therefore introduced other novel covers (e.g., plastic measuring cups) in sessions separate from the object-permanence trials.

Tasks $1-4$. Wok responded appropriately to all trials with familiar covers.

Tasks 5-8. Wok responded appropriately on most trials of these tasks. He had several mistrials during Tasks 7 and 8: he was more interested in the plastic measuringcup covers than in the hidden objects. He would ignore the actions of the investigators, then grab a cup and play with it for several minutes. He made one search error initially in each of Tasks 7 and 8 (searching the cup closest to him), but then correctly completed the requisite number of trials. In another session, he responded appropriately to all trials of Task 8.

Task 9 . The first trial was interrupted by construction noises in an adjacent room, but Wok removed two of the 
three superimposed cups before becoming distracted. Additional trials proceeded without disturbance, and Wok responded correctly.

Tasks 10-13. Wok erred once each on Tasks 12 and 13. On Trial 2 of Task 12, he chose the cup that had been correct on the initial trial. He also had a mistrial on Task 13, when he ignored the task and played with the covers.

Task 14. On the first trial, for which we placed all the items on a paper-lined plastic tray, Wok pulled the paper out from under the covers, thus causing a mistrial. His next two responses were correct: once he searched under all the screens in order of hiding and once he searched directly under the correct screen.

Task 15. After one mistrial, in which he played with the cups used as covers, Wok-appropriately-searched under the cover where the object logically should have been hidden.

Bruce, the parakeet. Bruce seemed unperturbed by testing. Even our initial use of a cover that was too large for him to remove-a quarter of a cocktail napkin-did not prevent him from obtaining the hidden object; he pulled it from under the cover. He removed the covers when we subsequently used eighths of napkins or propped pieces of paper plates between him and the objects.

Bruce differed from Wok not only in his tractability. We did not often use food objects, because Bruce was most willing to do a task if it involved uncovering a hand mirror. Too, possibly because parakeets are ground feeders (Forshaw, 1969, 1973), he was more likely to work on the floor than on his cage or a perch.

Bruce died before he could complete the series. About a month before his death, he was uncooperative and appeared ill: during the last scheduled session, he ignored the hidden objects and the researchers. These behaviors could have been caused by the increasing difficulty of the task or the onset of ill health.

Tasks 1-4. Bruce watched and edged away from yarn as it moved around him, and watched as it was dropped past his perch. In Task 3 , he withdrew partially covered pieces of banana from under a cocktail napkin (see above). He occasionally shredded the napkins during and after the trials. For Task 4, we cut the napkin cover into eighths, and he responded appropriately to all trials.

Tasks 5-12. Bruce made only two errors on all trials of these tasks. One error occurred on the first trial of Task 6, when he searched randomly under both covers. The other error occurred on Trial 2 of Task 11, when he searched under the screen where the item had previously been found.

Tasks 13-15. Task 13 was the last task for which we obtained any data. During the last session, Bruce correctly completed three invisible displacements.

Yellow Bird, the cockatiel. Yellow Bird worked more rapidly than the other birds, but also spent relatively more time playing with the covers or in displacement behaviors (e.g., feeding) at the outset of the sessions. In contrast to the parakeet, he could easily lift the covers. Because he would manipulate small metallic objects, he was tested entirely with nonfood items: rings, hair clips, and a key chain.

\section{Series 1:}

Tasks 1-3. Yellow Bird responded appropriately to all trials of these tasks.

Task 4. Yellow Bird clearly erred once, by reacting to the disappearance of a ring without attempting its recovery. In another trial, he pulled at the cover but not strongly enough to get the ring; however, he then noticed, approached, and pecked at the ring that the experimenter was wearing.

Tasks 5-8. Yellow Bird made one error on the first trial of Task 6; as in Task 4, he reacted to loss but made no attempt at recovery.

Task 9. On the first trial, Yellow Bird lifted only two of the three covers. He did one trial correctly, engaged in displacement behaviors for several minutes, then completed the requisite number of trials.

Tasks 10-11. Yellow Bird was initially more interested in the covers than in the hidden objects, but he did complete the appropriate number of trials for these tasks.

Task 12. This task was presented in the same session as Tasks 10 and 11 . He chose the wrong screen three times before responding appropriately three times; he therefore did not meet criterion, although he did eventually complete the requisite number of trials. He appeared fatigued, and we ended the session.

Tasks 13-15. We advanced to the next tasks in the next session. His initial responses were not appropriate, although they were of considerable interest: he would carry the objects and covers to the edge of the table, drop them, watch the descent, and follow the experimenters' retrievals. ${ }^{2}$ Only after he lost interest in these procedures did he respond appropriately to the trials for these tasks.

\section{Series 2:}

Tasks 1-10. Yellow Bird reached criterion on all tasks during one session.

Tasks 11-13. Yellow Bird was uncooperative during most of the sessions devoted to these tasks. He again picked up, carried, and dropped the covers and the objects, and watched the experimenters' retrievals. He bobbed his head, banged his beak, and fluffed his feathers, although, unlike Wok, he did not try to avoid the experimenter or the apparatus. He would push a recently retrieved object under a cover or a nearby calendar. He made more errors on these tasks than he had on the first series. One session ended when he tried to bite the experimenter.

Tasks 14-15. In contrast to his behavior during the previous tasks, Yellow Bird-on a subsequent dayresponded immediately and appropriately on all trials. 


\section{Series 3:}

Tasks 1-7. Yellow Bird reached criterion on these tasks during one session. One mistrial could, however, be interpreted as a loss of interest in the object, rather than the task: on the first trial in Task 6, he responded to the disappearance of the object by walking away from the apparatus.

Tasks 8-11. After a mistrial on Task 8, Yellow Bird made only a single error: he lifted the wrong screen on the first trial of Task 11 .

Task 12. Although he responded appropriately on some trials, his responses were haphazard: he made several wrong choices and spent considerable time hiding the ring himself. Given his previously correct responses on the more complex tasks, his behavior was difficult to explain.

Tasks 13-15. Yellow Bird completed these tasks with no errors. He ended Task 15 by walking to the edge of the table to look in the experimenter's hand, which had been the means of transferring the hidden ring between covers.

\section{Additional trials:}

Yellow Bird's large numbers of errors on Task 12 were not easily explainable. Correct responses to the more difficult tasks presumes comprehension of the easier ones, and he had responded immediately and appropriately to the final tasks on all of the series. Moreover, 3 months later, during a brief retesting session on Task 12 , he made no errors on three trials. It is unlikely that, after a 3-month hiatus, training effects were responsible for this improvement. It is more likely that his previous errors were a function of our concentrating all the sessions into one 10-day period. During retesting, he did not engage in any displacement behaviors and the single task seemed to occupy his attention.

Fred, the Illiger macaw. Of all of the birds tested, Fred was the most cooperative. He would fly to the test site (a gym set) when the experimenters entered the house and would wait for trials to begin. Although he occasionally showed more interest in the covers than in the hidden objects, such behaviors were less frequent than for the other subjects.

Because there were sometimes intervals of 2 months between Fred's test sessions, we occasionally repeated several tasks at the outset of sessions to reacquaint him with the procedures. The repeats usually involved nonfood items.

Tasks 1-6. Fred's first and only error was on Task 6: on his initial trial, he picked the closest cover first.

Tasks 7-9. Task 7 requires five correct consecutive searches. Fred responded correctly three times and then began to shred the paper covers and ignore the hidden objects (mistrials). We proceeded to the more complex Tasks 8 and 9 , on which he responded correctly on all trials. Task 7 was repeated during the next session, which occurred 1 month later; he responded appropriately on all trials.
Task 10. On two trials of this invisible displacement, Fred chose the cover under which the object was finally placed; on one trial, he checked the implementing container first. Both responses were appropriate (Uzgiris \& Hunt, 1975).

Tasks 11-12. After two mistrials on Task 11, in which Fred grabbed at both covers, he responded appropriately to all trials.

Task 13. Two months elapsed before we could administer Task 13. Fred erred once, on the second trial, choosing the wrong cup. He then responded appropriately five times, interrupting the procedures only once. This interruption was, however, of considerable interest: he flew from his gym to the floor to search beneath the coffee table where he had seen his owner place a cup of seeds before testing began.

Task 14. After another 2-month lapse, Fred immediately and correctly responded on all trials. His behavior on one trial suggested that odor cues were unimportant: he walked onto the seed cache after uncovering it and only moved back and began to eat after we tapped the table behind him.

Task 15 . Fred initially chose the last cover, where the object should logically have been; the object had, as required by Uzgiris and Hunt (1975), been left under the first cover. On a subsequent trial, he again searched appropriately, then went to the edge of the table to stare at the experimenter's hand, which had been the implementing container.

\section{GENERAL DISCUSSION}

Three different psittacids exhibited full Stage 6 object permanence. The 4th bird, a parakeet, performed at comparable levels on the tasks that were administered before its demise. Our results therefore demonstrate that awareness of object permanence is not limited to mammals, but is also present in certain birds.

Learning whether or not an animal comprehends object permanence was not the only purpose of our study. Because object permanence occurs in conjunction with other skills that may influence or be influenced by its occurrence, studies on object permanence also allow us to examine these interrelations. Some of these interrelated skills, such as language behaviors, are associated predominantly (but not exclusively) with humans; others, such as those involving functional and spatial organization, are acquired by most animals but to varying degrees (see Vauclair, 1982). Results from avian subjects might therefore provide important insights and suggest implications for research on the interrelation of these skills in other subjects.

\section{Effect of Language-Like Training}

Some researchers (e.g., Hall et al., 1980; Premack, 1983,1986 ) claim that training on language or language- 
like tasks facilitates conceptual thinking and would likely affect the results of object-permanence studies. Our nonlanguage-trained subjects, however, exhibited the same Stage 6 capacities as did Alex, the language-trained African Grey studied by Pepperberg and Kozak (1986). It is therefore possible that object-permanence tasks do not require the level of conceptual ability that is affected by language-like training. Language training may, for example, help a subject form a precise representation of the hidden object (see Vygotsky, 1962), but a subject in the Uzgiris and Hunt (1975) tasks need not have a representation of the specific hidden object-only that something has disappeared. Non-language-trained birds also may successfully complete even the more advanced sorting tasks of the Piagetian preoperational period (see ChardardSegurel, 1984; Hall et al., 1980; Hall et al., 1982; cf. Braggio, Hall, Buchanan, \& Nadler, 1982). The point at which language-like training affects object concept is not, therefore, easily established (Premack, 1983).

Whatever the effect of language training on mental capacity, the ability to communicate with a subject in a language-based code can affect the ease and speed of object-permanence testing. Vocal signals such as "Pay attention!" or "Go find the cork" would refocus the attention of the trained African Grey, Alex, when he began to ignore the apparatus (e.g., by beginning to preen). He could thus be given 1-2 min to complete a search, and disinterested behaviors were not immediate grounds for a mistrial. In contrast, we could use vocal signals with the subjects of the present study only to direct them to begin a search, not to bring them back to the task: they either searched for the item within $30 \mathrm{sec}$ or did not respond at all.

\section{Testing a Constellation of Abilities and Individual Traits}

Tests of object permanence actually test a constellation of attributes and abilities: motor skills, motivation, attention, memory, and socialization (for animals, tractability). Some of these abilities (motor skills) are likely to be independent of a concept of object permanence, whereas others (memory) are closely correlated with such a concept. Many researchers, therefore, have argued that the Piagetian framework in general-and the Uzgiris and Hunt (1975) tasks specifically-do not facilitate finegrained comparative studies.

The Uzgiris and Hunt (1975) tasks, for example, often do not distinguish between comprehension of object permanence and the physical ability needed to perform the task (note Doré \& Dumas, 1987; Flavell, 1985). The parakeet in the present study, for example, could not remove the cocktail-napkin cover initially used in Task 3; he instead removed the object from under the napkin. His behavior indicated a sense of object permanence, but would have been ineffectual with Task 9 . The Uzgiris and Hunt tasks, therefore, must be constructed and administered so that comprehension and physical competence are not confounded.
A subject's motivation to search for the hidden objects can affect the results of object-permanence testing, although motivation is not a reflection of cognitive abilities (note Thinus-Blanc \& Scardigli, 1981). Birds in particular appear less motivated than children and nonhuman primates to search for a hidden toy, although several avian species do manipulate objects in apparently playful behaviors (see Pepperberg, 1989), and our subjects would engage in a search if the objects were varied from trial to trial. Food items were not particularly potent reinforcers, probably because our subjects were well-fed pets. Occasionally, our subjects would preferentially manipulate the objects used as covers, or would ignore the experimenters and all experimental materials. Such trials (counted as mistrials) clearly demonstrated a lack of motivation and not a lack of understanding of the task: the animals did not choose the wrong cover; rather, they chose not to participate.

The extent to which a subject attends to the tasks also affects the results. Attention can be divided into two parts: (1) the attention span, or the length of time that a subject will devote to a task; and (2) how well the subject notices and processes the information being presented. Attention span need not be related to cognitive capacity, but the quality of attention may be indicative of such capacity. Both forms can vary not just between but within subjects. Attention span varied considerably within the subjects in our study. Yellow Bird, for example, in a single 1-h session, performed 10 tasks, but he completed no tasks in a subsequent session because he would not attend to the task. Similar variations occurred for the other birds. The quality of the attention that our subjects devoted to the tasks was less easy to document. The Uzgiris and Hunt (1975) tasks, for example, do not demonstrate whether the subjects are searching just for something of interest or for the particular object that had been hidden. A search for the latter would suggest that they had attended to and coded the specific attributes of the object as well as its spatial representation, and would demonstrate a complete understanding of object permanence: not just that an object maintains its existence when out of sight, but also that the found item is identical to the one hidden (note Flavell, 1985). This latter level of comprehension can be demonstrated by substituting different objects during invisible displacements and noting whether the subjects are surprised at finding something other than what had been hidden (see LeCompte \& Gratch, 1972). Tinklepaugh (1928, 1932) showed that monkeys and chimpanzees continued to search for the expected hidden object if it had been replaced with a less favored item. Repetition of the present study with this "substitution" protocol would be necessary to provide information as to the expectancies and quality of attention of our subjects.

Memory may affect the ability to respond correctly on object-permanence tasks. Bjork and Cummings (1984), for example, suggested that the Stage 4 " $\mathrm{AB}$ search error" (Task 6) often observed in children is a function of memory. The child continues to search where the object 
has been hidden and found on previous occasions, even though placement under a different cover is ciearly demonstrated. The subject thus seems not to remember information from the second hiding (see review in Flavell, 1985). Piaget does not consider this type of error to be related to memory. In his view, an $\mathrm{AB}$ error indicates that the object is seen as an integral part of the hiding place, rather than as something with an independent existence; that is, the error is based on an incomplete comprehension of object permanence. But the error may cease to occur if an infant is allowed to search immediately after the object is hidden in the second location (i.e., without any delay), if the discriminability of the covers is increased, or if removal of the covers is simplified. Moreover, when children have more than two choices of cover, their errors are not all to the previous location, but instead are clustered around the correct choice (Bjork $\&$ Cummings, 1984). We used only two choices of cover and allowed immediate searches (as specified by Uzgiris and Hunt, 1975); Bruce, Yellow Bird, and Fred picked the wrong cover on initial trials of Task 6, but not in subsequent trials. Bruce and Wok did make AB errors, but on Tasks 11 and 12, respectively, and not on Task 6 . Given our experimental design, our birds were unlikely to make their errors because of problems in remembering the location of the second hiding. ${ }^{3}$

In our study, socialization (or tractability) often determined whether a bird would be an appropriate subject and the ease with which it could be tested. Mistrials occurred when our subjects were frightened by external noises or novel covers (Wok), or when they chose to ignore the entire testing situation. Their patterns of behavior could be correlated to some degree with the extent to which they accepted strangers and novel situations-that is, their degree of socialization. It is unclear, however, whether there exists a correlation between the extent to which a subject can be socialized and the level of its cognitive achievement. Even if such a correlation exists, our conclusions would be unaffected by our choice of subjects on the basis of their sociability: our study was designed to test if these conceptual levels are within the capacity of a species (Triana \& Pasnak, 1981).

In sum, it is not always possible to disassociate the individual abilities that are tested during a study of object permanence, particularly if the study uses the tasks designed by Uzgiris and Hunt (1975). Despite the limitations of that scale for individual comparisons of each of the relevant abilities (e.g., see Bower, 1982; Flavell, 1985), the tasks nevertheless provide a standardized means for assessing cross-species similarities and differences for the constellation of capacities. As such, the tasks provide an important starting point for more detailed cross-species comparisons of cognitive capacities.

\section{Effects of Training and Learning \\ on Success in Object-Permanence Tasks}

In addition to the questions concerning which capacities are being examined during testing for object permanence, another question arises as to whether the proce- dures assess existing capacities or, instead, actually teach the concept (see Cornell, 1978; Hediger, 1981; Thomas \& Walden, 1985). It is, for example, possible that (1) subjects could learn the task from observing the experimenters' behaviors, (2) the repetitions of the tasks and even the mistrials allow subjects to engage in trial-anderror learning of each task (note Doré \& Dumas, 1987), or (3) the tasks provide a step-by-step program for teaching the concept. Analysis of our procedures and results suggests that our study did indeed assess existent abilities.

We were particularly careful to ensure that our birds were not being shown the correct response to any task. When a bird did not respond within $30 \mathrm{sec}$, the cover was not-as in some studies (Uzgiris \& Hunt, 1966)-lifted in the bird's presence. Instead, both the cover and the object were removed and only then was the object displayed for another trial. Furthermore, our subjects were not likely to have learned to respond to perceptual cues (e.g., to the location at which the object was hidden) because none of our subjects was shown an object being hidden more than once in any location on a trial in a given session.

Although it was impossible to ensure that one-trial learning was not taking place, the pattern of errors was generally inconsistent with an interpretation based on trial-anderror learning for the individual tasks. Had our subjects competence on object-permanence tasks been a product of learning, there would have been such evidence in the data from Yellow Bird, who was the one subject to perform the tasks three times. He did not, however, improve from the first series to the next; in fact, he made some mistakes on previously correct tasks (Tasks 11 and 13). He did improve on the third series, but not dramatically so. Even on this series, however, his mistakes were not grouped at the beginning and then reduced as one would expect if he were learning a concept. For the other subjects as well, choices did not get better with the number of repetitions. Thus, although tasks were repeated several times to show that chance was not a factor, such repetitions did not necessarily improve performance.

For our subjects, the tasks did not seem to provide a stepwise means of learning the concept of object permanence. Success on the later tasks did not appear to be dependent upon success on the earlier ones. Yellow Bird made more mistakes in the later, more difficult tasks in all series, but he and another subject also responded correctly on more complex tasks prior to their completing simpler ones: Fred reached criterion on Tasks $8-10$ before Task 7, and Yellow Bird completed Tasks 13-15 before he was retested on Task 12. Experience on the simpler tasks did, however, teach our subjects that the experimenters and the apparatus were nonthreatening. Such learning did not affect our assessment of existent abilities, but did facilitate our efforts to perform such an assessment.

\section{Implications of Having a Concept of Object Permanence}

Most animals, including humans, are not born with a concept of object permanence but acquire some sense of 
it over time. Not all six stages of object permanence are reached by all animals, and these stages may be reached by different processes, at different times, or with more or less difficulty (Chevalier-Skolnikoff, 1989). What, then, are the implications of demonstrating a particular level of understanding of object permanence?

Most researchers interpret the results of objectpermanence studies in one of two ways. Some view the stage attained by a subject as a correlate of the level of species-specific "practical intelligence" that an organism must attain in order to survive-that is, as the most basic of necessary processes (e.g., Scarr-Salapatek, 1976). Others view the acquired levels as indicative of the relative general cognitive capacities of the species (e.g., Thinus-Blanc, Poucet, \& Chapuis, 1982).

Tasks such as those devised by Uzgiris and Hunt (1975), however, reveal behavioral characteristics that are not necessarily species-specific or general; rather, these tasks allow the individual subjects to demonstrate particular characteristics that have been acquired through interactions within their specific social and physical environment-an environment that might be either considerably richer or more impoverished than one they might experience in nature (Doré \& Dumas, 1987; Gollin, 1985; Pepperberg \& Kozak, 1986). The ability of psittacine birds to demonstrate full Stage 6 object permanence is thus not necessarily a reflection of the evolutionary adaptive value of such a trait, nor of these animals' cognitive similarity to certain mammals. Rather, the level is indicative of their individual ability both to assimilate and to use available environmental information (Piaget, 1954). A psittacid that lacked the appropriate environmental information (that had, for example, been kept locked in a cage in the back room of a pet store) might not have demonstrated the same level of achievement. Data from tasks such as those of Uzgiris and Hunt therefore cannot directly indicate similarities and differences in general or practical cognitive capacities among species. Researchers such as Rozin (1976), however, have proposed a connection between success on object-permanence tasks and general abilities: they expanded on Piaget's discussion of assimilation and use of information to suggest that general intelligence is the ability to use information acquired in one (environmental) domain to solve problems in another. At the very least, data from object-permanence tests are likely to encourage research into the strategies and mechanisms that subjects use to solve these tasks, and thus lead to more detailed cross-species comparisons.

\section{REFERENCES}

BALDA, R. P. (1980). Recovery of cached seeds by a captive Nucifraga caryocatastes. Zeitschrift fur Tierpsychologie, 52, 331-346.

BAteson, P. (1979). How do sensitive periods arise and what are they for? Animal Behaviour, 27, 470-486.

BJork, E. L., Cummings, E. M. (1984). Infant search errors: Stage of concept development or stage of memory development. Memory \& Cognition, 12, 1-19.
Bossema, I. (1979). Jays and oaks: An eco-ethological study of a symbiosis. Behaviour, 70, 1-117.

Bower, T. G. R. (1982). Development in infancy. San Francisco: W. H. Freeman.

Braggio, J. T., Hall, A. D., Buchanan, J. P., \& Nadler, R. D. (1982). Logical and illogical errors made by apes and children on a cognitive task. Journal of Human Evolution, 11, 159-169.

BURGHARDT, G. M. (1984). Animal awareness: Current perceptions and historical perspective. American Psychologist, 40, 905-919.

Chardard-Segurel, C. (1984). Possibilités d'abstraction de différentes qualités sensibles chez le perroquet gris (Psittacus erithacus) en référence à l'enfant humain. Doctoral dissertation, Université de Sorbonne, Paris.

Chevalier-Skolnikoff, S. (1976). The ontogeny of primate intelligence and its implications for communicative potential. In S. Harnad, H. Steklis, \& J. Lancaster (Eds.), Origins and evolution of language and speech (pp. 173-211). New York: Annals of the New York Academy of Sciences.

Chevaluer-Skolnikorf, S. (1981). The Clever Hans phenomenon, cuing and ape signing: A Piagetian analysis of methods for instructing animals. In T. A. Sebeok \& R. Rosenthal (Eds.), The Clever Hans phenomenon (pp. 60-93). New York: Annals of the New York Academy of Sciences

Chevalier-SxolnikofF, S. (1989). Spontaneous tool use and sensorimotor intelligence in Cebus compared with other monkeys and apes. Behavioral \& Brain Sciences, 12, 561-627.

Chevaler-Skolnikoff, S., \&oirier, F. E. (1977). Primate bio-social development: Biological, social, and ecological determinants. New York: Garland.

CoRNell, E. H. (1978). Learning to find things: A reinterpretation of object permanence studies. In L. S. Siegel \& C. J. Brainerd (Eds.), Alternatives to Piaget: Critical essays on the theory (pp. 1-10). New York: Academic Press.

DorÉ, F. Y., \& Dumas, C. (1987). Psychology of animal cognition: Piagetian studies. Psychological Bulletin, 102, 219-233.

EtIENNE, A. S. (1973a). Developmental stages and cognitive structures as determinants of what is learned. In R. A. Hinde \& J. Stevenson (Eds.), Constraints on learning (pp. 371-395). New York: Academic Press.

ETIENNE, A. S. (1973b). Searching behavior towards a disappearing prey in the domestic chick as affected by preliminary experience. Animal Behaviour, 21, 749-761.

ETIENNE, A. S. (1976-1977). L'étude comparative de la permanence d'objet chez l'animal. Bulletin de Psychologie, 327, 187-197.

Flavell, J. H. (1985). Cognitive development. Englewood Cliffs, NJ: Prentice-Hall.

FLETChER, H. (1965). The delayed response problem. In A. Schrier, H. Harlow, \& F. Stollnitz (Eds.), Behavior of nonhuman primates (pp. 129-166). New York: Academic Press.

Forshaw, J. (1969). Australian parrots. Melbourne: Lansdowne Press. Forshaw, J. (1973). Parrots of the world. Garden City, NY: Doubleday.

GoLLIN, E. S. (1985). Ontogeny, phylogeny, and causality. In E. S. Gollin (Ed.), The comparative development of adaptive skills: Evolutionary implications (pp. 1-17). Hillsdale, NJ: Erlbaum.

Hall, A. D., Braggio, J. T., Buchanan, J. P., \& Nadler, R. D. (1982). Partitioning the influence of level from rate factors on the performance of children and apes on a cognitive task. Journal of $\mathrm{Hu}$ man Evolution, 11, 335-348.

Hall, A. D., Braggio, J. T., Buchanan, J. P., Nadler, R. D., KaRAN, D., SAMS, J. B. (1980). Multiple classification performance of juvenile chimpanzees, normal children, and retarded children. In ternational Journal of Primatology, 1, 345-359.

Hallock, M. B., Worobey, J. (1984). Cognitive development in chimpanzee infants (Pan troglodytes). Journal of Human Evolution, 13, $441-447$

Harriman, A., Berger, R. (1986). Olfactory acuity in the common raven (Corvus corax). Physiology \& Behavior, 36, 257-262.

HARRIS, P. L. (1983). Infant cognition. In M. M. Haith \& J. J. Campos (Eds.), Handbook of child psychology: Infancy and developmental psychology (Vol. 2, pp. 689-782). New York: Wiley. 
Hediger, H. K. P. (1981). The Clever Hans phenomenon from an animal psychologist's point of view. In T. A. Sebeok \& R. Rosenthal (Eds.), The Clever Hans phenomenon (pp. 1-17). New York: Annals of the New York Academy of Sciences.

KAmil, A. C., BALDA, R. P. (1985). Cache recovery and spatial memory in Clark's nutcrackers (Nucifraga columbiana). Journal of Experimental Psychology: Animal Behavior Processes, 11, 95-111.

KOEHLER, O. (1943). "Zahl'-Versuche an einem Kolkraben und Vergleichsversuche an Menschen. Zeitschrift für Tierpsychologie, 5, 575-712.

KOEHLER, O. (1950). The ability of birds to "count." Bulletin of Animal Behaviour, 9, 41-45.

Kolar, K. (1972). Der Papageien. In Grzimek's Tierleben VIII, Munich: Kindler-Verlag; English translation, van Nostrand Reinhold.

Kroodsma, D. E. (1982). Learning and the ontogeny of sound signals in birds. In D. E. Kroodsma \& E. H. Miller (Eds.), Acoustic communication in birds (Vol. 2, pp. 1-23). New York: Academic Press.

Kroodsma, D. E., BAker, M. C., BAPtista, L. F., Petrinovich, L. (1984). Vocal "dialects" in Nuttall's white-crowned sparrows. Current Ornithology, 2, 103-133.

LeCompte, G. K., \&RATCH, G. (1972). Violation of a rule as a method of diagnosing infants' levels of object concept. Child Development, 43, 385-396.

LORENZ, K. (1970). Studies in animal and human behavior (Vol. 1). Cambridge, MA: Harvard University Press.

MACPHAIL, E. (1982). Brain and intelligence in vertebrates. Oxford: Oxford University Press.

MacphaIL, E. (1987). The comparative psychology of intelligence. Behavioral \& Brain Sciences, 10, 645-695.

Parker, S. T., \& Gibson, K. R. (1977). Object manipulation, tool use and sensorimotor intelligence as feeding adaptations in Cebus monkeys and great apes. Journal of Human Evolution, 6, 623-641.

Pepperberg, I. M. (1979, June). Functional word use in an African Grey parrot. Paper presented at the annual meeting of the Animal Behavior Society, New Orleans.

PepperberG, I. M. (1981). Functional vocalizations by an African Grey parrot (Psittacus erithacus). Zeitschrift fur Tierpsychologie, 55, 139-160.

Pepperberg, I. M. (1983). Cognition in the African Grey parrot: Preliminary evidence for auditory/vocal comprehension of the class concept. Animal Learning \& Behavior, 11, 179-185.

Pepperberg, I. M. (1987a). Evidence for conceptual quantitative abilities in the African Grey parrot: Labeling of cardinal sets. Ethology, 75, 37-61.

PepperberG, I. M. (1987b). Interspecies communication: A tool for assessing conceprual abilities in the African Grey parrot (Psittacus erithacus). In G. Greenberg \& E. Tobach (Eds.), Language, cognition, consciousness: Integrative levels (pp. 31-56). Hillsdale, NJ: Erlbaum.

PePperberg, I. M. (1989). Tool use in birds: An avian monkey wrench? Behavioral \& Brain Sciences, 12, 604-605.

Pepperberg, I. M. , Kozak, F. A. (1986). Object permanence in the African Grey parrot (Psittacus erithacus). Animal Learning \& Behavior, 14, 322-330.

PIAGET, J. (1953). Origin of intelligence in the child. London: Routledge \& Kegan Paul.

PIAGET, J. (1954). The construction of reality in the child. New York: Basic Books.

PIAGET, J. (1971). Biology and knowledge. Chicago: University of Chicago Press.

PIAGET, J. (1978). Behavior and evolution. New York: Pantheon.

PIAGET, J. (1980). Adaptation and intelligence: Organic selection and phenocopy. Chicago: University of Chicago Press.

PRemack, D. (1983). The codes of man and beasts. Behavioral \& Brain Sciences, 6, 125-167.

Premack, D. (1984). Upgrading a mind. In T. G. Bever, J. M. Carroll, \& G. A. Miller (Eds.), Talking minds (pp. 181-206). Cambridge, MA: MIT Press.

Premack, D. (1986). Gavagai. Cambridge, MA: MIT Press.

Redshaw, M. (1978). Cognitive development in human and gorilla infants. Journal of Human Evolution, 7, 133-141.
RENSCH, B. (1956). Increase of learning capability with increase in brain size. American Naturalist, 90, 81-95.

RozIN, P. (1976). The evolution of intelligence and access to the cognitive unconscious. In J. M. Spraque \& A. N. Epstein (Eds.), Progress in psychobiology and physiological psychology (Vol. 6, pp. 245-280). New York: Academic Press.

SCARR-SalaPatex, S. (1976). An evolutionary perspective on infant intelligence: Species patterns and individual variations. In $\mathbf{M}$. Lewis (Ed.), Origins of intelligence (pp. 165-197). New York: Plenum.

SHERRY, D. F. (1982). Food storage, memory, and marsh tits. Animal Behaviour, 30, 631-633.

SherRY, D. F. (1984). Food storage by black-capped chickadees: Memory for the location and contents of caches. Animal Behaviour, $32,451-464$.

Shettleworth, S., KreBs, J. (1982). How marsh tits find their hoards: The roles of site preference and spatial memory. Journal of Experimental Psychology: Animal Behavior Processes, 8, 354-375.

SHETTLEWORTH, S., \& KREBS, J. (1986). Stored and encountered seeds: A comparison of two spatial memory tasks in marsh tits and chickadees. Joumal of Experimental Psychology: Animal Behavior Processes, 12, 248-257.

StettNer, L. J., Matyniak, K. (1968). The brain of birds. Scientific American, 218, 64-76.

Thinus-Blanc, C., Poucet, B., Chapuis, N. (1982). Object permanence in cats: Analysis in locomotor space. Behavioural Processes, 7, 81-86.

Thinus-Blanc, C., SCardigl, P. (1981). Object permanence in the golden hamster. Perceptual \& Motor Skills, 53, 1010

Thomas, R. K., \& WALDEN, E. L. (1985). The assessment of cognitive development in human and nonhuman primates. In E. Watts (Ed.), Nonhuman primate models for human growth and development (pp. 187-215). Atlanta: Alan R. Liss.

TINKLEPAUGH, O. T. (1928). An experimental study of representative factors in monkeys. Joumal of Comparative Psychology, 8, 197-236.

Tinklepaugh, O. T. (1932). Multiple delayed reaction with chimpanzees and monkeys. Journal of Comparative Psychology, 13, 207-243.

Triana, E., Pasnak, R. (1981). Object permanence in cats and dogs. Animal Learning \& Behavior, 9, 135-139.

UzGIRIs, I. C., \& HuNT, J. McV. (1966). Ordinal scales of infant development, No. 1-Object permanence [Film]. Champaign, IL: University of Illinois Films.

UzGIRIs, I. C., HUNT, J. McV. (1975). Assessment in infancy: Ordinal scales of psychological development. Champaign-Urbana, IL: University of Illinois Press.

VANDER WALL, S. B. (1982). An experimental analysis of cache recovery in Clark's nutcrackers. Animal Behaviour, 30, 84-94.

VAUCLAIR, J. (1982). Sensorimotor intelligence in human and non-human primates. Journal of Human Evolution, 11, 257-264.

Vygotsky, L. (1962). Thought and language. Cambridge, MA: MIT Press.

WADSWORTh, B. J. (1984). Piaget's theory of cognitive and affective development. New York: Longman.

Wellman, H. M., Cross, D., \& Bartsch, K. (1986). Infant search and object permanence: A meta-analysis of the A-not-B error. Monographs of the Society for Research in Child Development, 51(3, Serial No. 214).

Wood, S., Moriarty, K. M., Gardner, B.T., \& Gardner, R. A. (1980). Object permanence in child and chimpanzee. Animal Learning \& Behavior, 8, 3-9.

Zentall, T. R., Edwards, C. A., Moore, B. S., Hogan, D. E. (1981). Identity: The basis for both matching and oddity leaming in pigeons. Journal of Experimental Psychology: Animal Behavior Processes, 7, 70-86.

Zentall, T. R., Hogan, D. E. (1974). Abstract concept learning in the pigeon. Journal of Experimental Psychology, 102, 393-398.

\section{NOTES}

1. The following behaviors demonstrate Stages 5 and 6 understanding of object permanence. Stage 5 (considers sequential displacements while searching for vanished objects): nutcrackers, prevented from cach- 
ing but allowed to watch other birds cache and recache seeds, recovered seeds at levels above chance (Vander Wall, 1982). Stage 6 (images of absent objects, representations of displacements): (1) interocular transfer tests show that marsh tits rely on information stored in their brain to recover caches (Sherry, 1982); (2) marsh tits avoid already emptied caches during a second recovery session, suggesting that their behavior is based on memory rather than on simple nules of movement; this behavior also indicates a memory for displacement (Sherry, 1982); (3) chickadees that cache two different types of food recover their favored food first, suggesting memory for the particular type of food cached, rather than for just "something of interest" (Sherry, 1984); (4) nutcrackers persist in searching areas where they have cached seeds even when the experimenter has removed the seeds to prevent odor cues (a test comparable to Task 15 of Uzgiris \& Hunt, 1975); such recovery is, however, disrupted when local landmarks are moved or removed (Balda, 1980; Vander Wall, 1982).

2. Yellow Bird's behaviors, as well as his later repeated hiding of an object under a calendar after retrieving it, are "tertiary circular reactions" that indicate Stage 5 competence in another Uzgiris and Hunt (1975) series, "The Construction of Object Relations in Space." Such behaviors are important to note because they were thought to be limited to hominids (Parker \& Gibson, 1977).

3. Wellman, Cross, and Bartsch (1986), however, proposed that memory plays only a small role in the AB error. They suggested that the error comes from an incompletely developed ability to process spatiotemporal information-that is, a problem in understanding object movement. The small number of $\mathrm{AB}$ errors in our study suggests that these birds could correctly process spatiotemporal information.

\section{APPENDIX}

Scale I: The Development of Visual Pursuit and the Permanence of Objects, from Uzgiris and Hunt (1975) and Wood et al. (1980)

A. Visual pursuit of slowly moving objects

1. Follows a slowly moving object through a $180^{\circ}$ arc (3-4)

a. Does not follow object

b. Follows jerkily through part of arc

c. Follows smoothly through part of arc

*d. Follows object smoothly through complete arc

2. Noticing the disappearance of a slowly moving object (3-4)

a. Does not follow to point of disappearance

b. Loses interest as soon as object disappears

*c. Lingers with a glance on point of disappearance

*d. Returns glance to starting point after several presentations

e. Searches around point of disappearance

B. Search for simply hidden objects

3. Finding an object that is partially covered (3)

a. Loses interest

b. Reacts to the loss, but does not obtain object

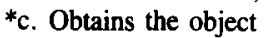

4. Finding an object that is completely covered (3)

a. Loses interest

b. Reacts to loss, but does not obtain object

c. Pulls screen, but not enough to obtain object

*d. Pulls screen off and obtains object
5. Finding an object completely covered in two places (2)

a. Loses interest

b. Searches for object where it was previously found (with respect to location)

${ }^{*} \mathrm{c}$. Searches for object where it is last hidden

6. Finding an object completely covered in two places alternately (3-5)

a. Becomes perplexed and loses interest

b. Searches haphazardly under one or both screens

${ }^{*} c$. Searches correctly under each of the screens

7. Finding an object completely covered in three places (5-7)

a. Loses interest

b. Searches haphazardly under some or all screens

*c. Searches directly under the correct screen

C. Search following more complex hidings

8. Finding an object after successive visible displacements (3-5)

a. Does not follow successive hidings

b. Searches only under the first screen

c. Searches under screen where object was previously found

d. Searches haphazardly under all screens

e. Searches in order of hiding

*f. Searches directly under the last screen in path

9. Finding an object under three superimposed screens (2-3)

a. Loses interest

b. Lifts one or two screens, but fails to find object

${ }^{*} \mathrm{c}$. Removes all screens and obtains object

D. Search following an invisible displacement

10. Finding an object following one invisible displacement (3)

a. Loses interest

b. Reacts to loss, does not search

c. Searches only in the box

*d. Checks the box and searches under the screen

*e. Searches under the screen directly

11. Finding an object following one invisible displacement with two screens (2)

a. Searches only in the box

b. Searches under screen where object was previously found

*c. Searches directly under correct screen

12. Finding an object following one invisible displacement with two screens alternated (3)

a. Loses interest

b. Searches haphazardly under all screens

*c. Searches directly under correct screen

d. Other-searches under screen where last found

13. Finding an object following one invisible displacement with three screens (5-7)

a. Loses interest

b. Searches haphazardly under all screens 
*c. Searches directly under correct screen

E. Search following successive invisible displacements

14. Finding an object following a series of invisible displacements (4-6)

a. Searches only in experimenter's hand

b. Searches only under first one or two screens in the path

${ }^{*} c$. Searches under all screens in the path in the order of hiding

*d. Searches directly under the last screen in the path

15. Finding an object following a series of invisible displacements with evidence of representation (2) a. Searches only under last screen

b. Searches haphazardly under all screens

*c. Searches systematically from the last screen to the first

Note-The number in parentheses following each task description indicates the number of repetitions of the task recommended by Uzgiris and Hunt. An asterisk indicates the action that must be performed for achievement of a step of the scale.

(Manuscript received April 27, 1989;

revision accepted for publication August 12, 1989.) 